into account the costs of alternative forms of treatment. My impression is that the second argument carried the day.

The discussions reveal a group of very thoughtful individuals wrestling with the problems of an extraordinary health care system. For example, Lucy Johns, consultant in health care planning and policy in San Francisco, pointed out that health care was a major employer with many people being very happy with the present arrangement. A basic benefit plan would potentially deprive health care staff of income and would not be accepted without a fight. A manager of a state employees association expressed concern that clinical guidelines should not limit the services available to less affluent citizens. He favoured a single tier health care system, and the counterargument was that single tier health care would not be acceptable in the United States and that the aim should be to provide adequate care to all, with any additional care being of only marginal value or even harmful. The buying behaviour of the rich, including that towards health care, is foolish, it was claimed, but a large part of the health care system seems willing to benefit from this foolishness. The role of guidelines in litigation was raised, with one member of the audience suggesting that $20 \%$ of health care costs could be ascribed to defensive medicine. If guidelines are to be successful in such an environment they will need some legislative support. A remark from the California State Employees Association's speaker is worth repeating: "Rationing is not the answer until we have some cost controls and business and labour are interested and willing to help do their part in controlling costs."

It is quite bizarre that the United States manages to spend such a vast amount on health care with so little to show for it. It is claimed that $\$ 900$ of the sale price of each car produced by General Motors is devoted to the health costs of the company's employees. The medical profession, the insurance companies, and the providers who make profits seem to be too strong a lobby for rational change to take place. Yet it seems to me obscene that the service should be talking about rationing care when so much is spent on care that is of no value. Surely it is the responsibility of all of us to eliminate waste before restricting the availability of care that does have value.

Director, Eli Lilly National Medical Audit Centre

Free copies of this book may be obtained by calling (916) 3263387 or from Michelle Mitchell, Health Plan Administration Division, California PERS, Plan Administration Division, California PERS, PO Box

\section{MEETINGS REPORTS}

Healthy outcomes. Health $\begin{gathered}\text { Service } \\ \text { conference, } \\ \text { Journal } \\ \text { November } 1992\end{gathered}$

The healthy outcomes conference was a spirited and invigorating event designed to challenge the current enthusiasm for health outcomes - as a means of measuring success in health service management, as a method for quality assurance, and as a way of involving consumers more closely in decisions about how much and what health services are available. For an initiative which is profoundly interprofessional, requiring the skills of academics - researchers and economists public health specialists, managers of health services, and clinicians, the conference did well in attracting a representative audience and an appropriate cross section of speakers, including experience and - it has to be said - energy from the United States.

The event raised the many practical issues surrounding the outcomes movement in the UK. Do we have the information systems to link people's initial symptoms and signs with their eventual health outcome? Do we have the expertise to understand the likely causal relations between health care inputs and health outcomes? Can we predict the outputs per unit of input? Do we understand enough about the influence of confounding variables such as disease severity, coexisting disease, age, income, and social class to make inferences about cause and effect? How will developing information and existing but unused information support priority setting by purchasers and quality management by providers?

Overriding these issues was the assumption that the opportunities afforded by the NHS reforms to refocus the health service toward a greater appreciation of the population's health values should be seized. The speakers raised ways of tackling the scientific questions. On the question of variations in health care $\mathrm{Klim}$ McPherson, professor of public health epdemiology, Health Promotion Sciences Unit, suggested a hierarchy of uncertainty which could begin to establish priorities for outcomes studies, arguing that poor consensus or a lack of information on effectiveness was likely to be a determinant of variable outcome in proportion to their significance to the health service. Trevor Sheldon, senior research fellow, Centre for Health Economics, York, gave a cogent account of the problem of confounding variables and bias in considering information on outcomes. $\mathrm{He}$ also pointed to the need for central initiatives, such as leadership to overcome the overbearing reliance by the treasury on activity and process measures in formulating the efficiency index for monitoring the NHS, and the need for a national audit on appropriateness.

In considering consumer focus $\mathrm{Kai}$ Rudat at Market Opinion Research International described work in progress to reshape patient satisfaction surveys to enhance their objectivity and to include clinical measures. This initiative is clearly to be welcomed as an off the peg approach which may be readily applied to several health care settings. Rabbi Julia Neuberger heralded the beginning of a refreshing and stimulating public debate which would engage those using health services, their families, and their carers in resolving issues of competing demand. Acknowledging the problem of scarce resources, she left us in no doubt who should answer the question of what works and what doesn't in health care. And with $\mathrm{Mr}$ Brendan Devlin declaring that quality of life should be measured routinely as an outcome measure for surgery with effort made to secure greater provision of information to patients it was beginning to look as though the day had been won.

Characteristically the speakers from the United States were provocative. Ira Raskin described the efforts of the Agency for Health Care Development and Research to establish patient outcomes research teams, a series of multidisciplinary research projects designed to evaluate health service interventions in areas of high cost, high variation, and high volume medical care. These included benign prostatic hypertrophy, low back pain, myocardial infarction, hip fracture and diabetes, which rely heavily on using information from the extensive Medicare database. Robert Brook from the Santa Monica based Rand Corporation began by claiming that there was no evidence that feedback of information on health status to clinicians would result in a change in behaviour; process information was needed to ensure that doctors conformed with best practice. His main concern was, however, to convince the audience of the value of publishing information on comparative performance to the public, although there is no evidence for the efficacy of this approach Nevertheless this perilous theme was taken up by several speakers and remains a challenge the Health Service fournal may be unable to resist.

ALISON FRATER Public Health Specialist

Advancing day surgery. North East and North West Thames Regional Health Authorities and NHS Management Executive, London, January

This seminar brought together clinicians, general managers, and chief executives to discuss the key issues of day surgery.

The speakers, from various professional backgrounds, each tackled the main issues from a different standpoint and offered practical advice in achieving a quality service in clinical care, management arrangements, and environment. The overriding concern of them all was that in the drive for efficiency and cost effectiveness emphasis must remain on quality.

The demand for day surgery is growing and it is important to make sure it is well managed. This means considering resources, the impact on the community as well as that on the rest of the hospital. Day surgery is not a short cut; more time is invested in informing patients and there is a higher cost and a higher time factor in communicating with GPs and community nurses. Paul Jarrett, a consultant surgeon, emphasised that day surgery units cannot be seen as a cost cutting exercise if quality is to be maintained, and David Wilkinson, a consultant anaesthetist, underlined the need for swift and accurate information to be received by GPs. The question of medical day care facilities was discussed by Mike Paul and Elspeth Alstead from Forest Healthcare NHS Trust. 